\title{
FACULTY AND STUDENT GOALS FOR UNDERGRADUATE LABORATORY ${ }^{\sharp}$
}

\author{
Marcy H. Towns \\ Purdue University, Department of Chemistry, 560 Oval Drive, West Lafayette, IN, USA, 47907
}

Recebido em 13/10/2016; aceito em 24/12/2016; publicado na web em 05/02/2017

\begin{abstract}
Laboratory is a part of most undergraduate chemistry curricula, however the goals that faculty and students hold have received scant attention. Our research has revealed two broad goals for laboratory learning held by faculty. Students however, hold entirely different goals that may pose obstacles for faculty achieving the goals they have set out. Herein we describe our research and propose methods of bringing these goals into better alignment.
\end{abstract}

Keywords: Undergraduate laboratory instruction, chemistry education research, first-year undergraduate, second-year undergraduate, upper-division undergraduate, general chemistry, organic chemistry

\section{INTRODUCTION}

\section{Role of Laboratory}

Laboratory at the university or tertiary level has been given a special role in the science curriculum around the globe. ${ }^{1-3}$ It would be rare to have a science course, such as a general chemistry course without an associated laboratory. However, numerous reviews of research on laboratory have called into question the impact of laboratory on student learning. . $2,4,5$ One can argue that perhaps the wrong questions have been asked given the unique nature of the laboratory environment. ${ }^{6}$

To address the gaps in the research that has been carried out in laboratory in 2005 we embarked with our collaborators on a research trajectory that would help us understand the goals that faculty and students have for laboratory. ${ }^{7-16}$ The ultimate goal has been to describe the correspondence between the two and to shape and guide the laboratory curriculum in ways that would bring about a better correspondence.

\section{FACULTY GOALS FOR LABORATORY}

We have carried out qualitative and quantitative studies to build an understanding of the faculty goals for undergraduate chemistry laboratory across the curriculum. ${ }^{7-9}$ Our results indicate that faculty have two broad goals for the undergraduate chemistry curriculum. They want students to learn hands-on techniques (and know when it is appropriate to use them) and to improve their critical thinking skills. ${ }^{7}$ These two goals change slightly as the student moves through the chemistry undergraduate curriculum. For example, at the general chemistry level students may be using balances, glassware, hot plates, and spectrophotometers. The goal in this case might be to have students use these devices and instruments safely and with accuracy and precision. During the last two years of a chemistry major's program a faculty member might have students preparing samples for analysis on a variety of instruments including an NMR, FTIR, ICP-MS, HPLC, or GC-MS. In all cases faculty might wish for students to know how to prepare samples, how to create a calibration

*e-mail: mtowns@purdue.edu

"This paper was presented in the SBQ - ACS symposium on Chemical Education, held in Goiânia, on May 2016. Publication costs were assisted by INCT Inomat, CNPq process 573644/2008-0 curve in the service of determining the concentration of an unknown, and/or how to correctly use the instrument. They would also expect for students to learn how to interpret data to obtain chemical and physical information about the system under investigation thus demonstrating that the student understands what type of data could be obtained from the instrument. These goals ultimately become connected to critical thinking as the data is analyzed and interpreted in order to test a hypothesis or answer a question.

We have also carried out a survey of chemistry faculty in the United States that are involved in teaching undergraduate laboratories. ${ }^{8}$ We analyzed the data such that we could determine where significant differences in faculty goals existed relative to courses in the undergraduate curriculum. What we discovered sheds light on what goals are emphasized at what times in the curriculum.

In general chemistry there is significantly less emphasis placed on students preparing students to engage in undergraduate research and research like experiences than in courses that follow in the curriculum. This result makes sense in the context of general chemistry courses in the United States which have a variety of majors (engineers, scientists, agriculture majors, business majors, future nurses, future teachers, etc.). Usually students in the United States take general chemistry their first (or freshman) year. Thus, the course attempts to meet learning outcomes for a mix of students who are pursing variety of majors. These courses also tend to have larger enrollments that those that follow in the curriculum. Only a small percentage of the students enrolled go on to become science majors or chemistry majors. Thus preparing all of them for undergraduate research experiences is not strongly emphasized relative to courses later in the curriculum. Also, the requirements in terms of equipment to carry out such experiences in a large enrollment course can render these goals impractical.

Our analysis revealed that faculty who teach general chemistry laboratory place significantly less emphasis on laboratory writing in terms of communicating science and keeping a laboratory notebook than in other courses in the curriculum. In the United States students frequently work in groups in general chemistry where they complete one laboratory report for the group rather than an individual report. The curricula may include laboratory report forms that the students complete that include data tables and questions that lead the students through data analysis and interpretation such that writing is de-emphasized.

Error analysis and uncertainty in measurement is significantly less emphasized in organic chemistry than in other courses in the 
curriculum. This may be due to the nature of organic courses which emphasize the learning of techniques and physical characterization of materials. The survey data also revealed that group work and communication skills are significantly less emphasized than in analytical chemistry and physical chemistry courses.

Based upon the results of this research we generated an evidenced based understanding of faculty goals for the undergraduate chemistry curriculum. Thus, we turned our research focus to investigating student goals for the undergraduate chemistry laboratory.

\section{STUDENT GOALS FOR LABORATORY}

Our research indicates that students across the curriculum wish to finish laboratory as expeditiously as possible with the highest possible marks on their laboratory reports. ${ }^{10.11}$ Although faculty wish to believe that students who are chemistry majors have goals that are not similar to students in general chemistry who wish to finish lab quickly and make the highest scores possible, in fact they do. Our research revealed students who work in groups routinely divide the workload in order to finish quickly. We have repeatedly observed that this behavior results upper-division students not learning hands-on skills with the equipment.

Additionally, we have found evidence that some students at the upper division level do not view laboratory as a place to apply critical thinking skills, integrate concepts, or develop conceptual knowledge. ${ }^{11}$ Rather the students focus on collecting data and leaving laboratory as quickly as possible. They plan to analyze and interpret data after laboratory and apply chemistry concepts at that time.

\section{CORRESPONDENCE BETWEEN GOALS AND RECOMMENDATIONS FOR TEACHING}

Based upon the findings of our research we have concluded that faculty and student goals for the laboratory are not well aligned and this may be a reason why previous studies have revealed the limited impact of laboratory on a host of student outcomes. Students tend to allow affective goals such as the desire to finish early with the highest grade possible to override goals related to cognitive outcomes. ${ }^{10,11}$ If the curriculum were to emphasize students setting goals for laboratory and monitoring and reflection activities were part of the post-laboratory activities this might address some of the misalignment through self-regulation of learning.

When working in groups the students will assign one or perhaps two people to handle the equipment and take measurements while the other students record data and begin the analysis. Thus, the development of hands-on skills and critical thinking skills is not uniform across the group. We have found that having the students work individually or directing students to assign roles in the laboratory addresses this disparity.

We have implemented digital badging as a method of ensuring that all students learn specific hands-on skills such as how to use a pipet, read a buret, or make a solution in a volumetric flask. ${ }^{17} \mathrm{~A}$ digital badge has specific data attached to it such as a student created video that serves as evidence of mastery of a specific skill. A digital badge can be created online with specific tasks the students must complete in order to demonstrate mastery of a skill or show evidence of achievement.

Galloway and Bretz have conducted ground breaking work with students in general chemistry and organic chemistry courses through a survey they developed to measure the student's inclination towards meaningful learning in the laboratory. ${ }^{12-16}$ The findings of a national study point toward emphasizing the affective domain specifically with emphasis on developing a "positive self-concept as a student of chemistry." Their work emphasizes the importance of allowing students to make decisions in laboratory whether it be about experimental design, analysis, interpretation, or communication. ${ }^{7,12-16}$

\section{CONCLUSIONS}

Our research has established a misalignment between student and faculty goals for laboratory that leads to faculty goals of learning hands-on skills and developing critical thinking skills being thwarted. To address this issue our research and that of the Bretz group indicates that altering the curriculum through activities such as digital badges or through engaging the students affectively may result in better alignment.

\section{REFERENCES}

1. Hofstein, A.; Lunetta, V. N.; Sci. Educ. 2004, 88, 28.

2. Hofstein, A.; Mamlok-Naaman, R.; Chem. Educ. Res. Pract. 2007, 8, 105.

3. Reid, N.; Shah, I.; Chem. Educ. Res. Pract. 2007, 8, 172.

4. Sevian, H.; Fulmer, G. W.; Educ. Quim. 2012, 23, 149.

5. Rice, J.; Thomas, S. M.; O’Toole, P.; Tertiary Science Education in the 21st Century; Australian Council of Deans of Science: Melbourne, Australia, 2009. Available at http://catalogue.nla.gov.au/Record/4733729 (accessed January 2017)

6. Nakhleh, M. B.; Polles, J.; Malina, E. In Chemical Education: Towards Research-Based Practice; Gilbert, J. K., De Jong, O., Justi, R., Treagust, D. F., Van Driel, J. H., eds.; Kluwer Academic Publishers: Dordrecht, 2002.

7. Bruck, L. B.; Towns, M.; Bretz, S. L.; J. Chem. Educ. 2010, 87, 1416.

8. Bruck, A.; Towns, M. H.; J. Chem. Educ. 2013, 90, 685.

9. Bretz, S. L.; Fay, M.; Bruck, L. B.; Towns, M. H.; J. Chem. Educ. 2013, 90,685 .

10. DeKorver, B. K.; Towns, M. H.; J. Chem. Educ. 2015, 92, 2031.

11. DeKorver, B. K.; Towns, M. H.; J. Res. Sci. Teach., 2016, 53, 1198.

12. Galloway, K. R.; Bretz, S. L.; Chem. Educ. Res. Pract. 2015, 16, 879.

13. Galloway, K. R.; Bretz, S. L.; J. Chem. Educ. 2015, 92, 1149.

14. Galloway, K. R.; Bretz, S. L.; J. Chem. Educ. 2015, 92, 2019.

15. Galloway, K. R.; Bretz, S. L.; J. Chem. Educ. 2015, 92, 2006.

16. Galloway, K. R.; Malakpa, Z.; Bretz, S. L.; J. Chem. Educ. 2016, 93, 227.

17. Towns, M.; Harwood, C. J.; Robertshaw, M. B.; Fish, J.; O’Shea, K.; J. Chem. Educ. 2015, 92, 2038. 